Tropical Journal of Pharmaceutical Research February 2011; 10 (1): 81-88

(C) Pharmacotherapy Group, Faculty of Pharmacy, University of Benin,

Benin City, 300001 Nigeria.

All rights reserved.

Research Article

Available online at http://www.tjpr.org

\title{
Colorimetric Determination of Cefadroxil and Ceftriazone in Pharmaceutical Dosage Forms
}

\author{
Ch Aswani Kumar, BM Gurupadayya*, S Navya Sloka, RS \\ Chandan and JC Thejaswini \\ Department of Pharmaceutical Analysis, JSS College of Pharmacy, JSS University, Mysore 570 015, (KA), India
}

\begin{abstract}
Purpose: To develop a simple, rapid and selective method for the spectrophotometric determination of cefadroxil and ceftriaxone using 1, 2- napthaquinone-4- sulfonic acid sodium.

Methods: The method was based on the derivatization of cefadroxil and ceftriaxone with 1, 2naphthaquinone-4- sulfonic acid sodium in alkaline medium to yield orange-colored products.

Results: The reaction products of cefadroxil and ceftriaxone at their respective $\lambda$ max of 475 and 480 $\mathrm{nm}$ showed linearity in the concentration range of $10-100$ and $25-175 \mu \mathrm{g} / \mathrm{ml}$, respectively. Relative standard deviations of $0.82 \%$ for cefadroxil and $0.95 \%$ for ceftriaxone were obtained. Recoveries of cefadroxil tablets and ceftriaxone injection were in the range of $100.66 \pm 0.98$ and $99.38 \pm 0.84 \%$, respectively.

Conclusion: Recovery studies gave satisfactory results indicating that none of the major additives/excipients interfered with the assay method. Therefore, the proposed method is simple, rapid, precise and convenient for the assay of cefadroxil and ceftriaxone in commercial preparations.
\end{abstract}

Keywords: Cephalosporins, Derivatization, 1, 2- Naphthaquinone 4- sulfonic acid sodium, Colorimetry, Pharmaceutical formulation. 


\section{INTRODUCTION}

Cefadroxil (CFL) is chemically designated as 8-[2-amino-2-(4-hydroxyphenyl)acetyl]amino-4-methyl-7-oxo-2-thia-6azabicyclo[4.2.0]oct-4-ene-5-carboxylic acid. It is a first generation cephalosporin antibacterial drug that is the para-hydroxy derivative of cefalexin, and is used in the treatment of mild to moderate susceptible infections. It is a broad spectrum bactericidal antibiotic that is effective against many Grampositive and Gram-negative bacteria, including Staphylococcus aureus, Streptococcus pneumoniae, Streptococcus piogenes, Moraxella catarrhalis, Escherichia coli, Klebsiella and Proteus mirabilis [1].

A wide variety of analytical methods have been reported for the determination of CFL in pure form, in pharmaceutical preparations and in biological fluids. These methods mainly involve spectrophotometry [2], atomic absorption spectrophotometry [3], fluorometry [4], chemiluminescence [5], polarography [6], high performance liquid chromatography [7], and capillary electrophoresis [8]. CFL and cefotaxime have been determined by flow injection spectrophotometric method [9].

Some methods have been developed for the simultaneous determination of CFL when combined with other drugs in various dosage forms. CFL and cefotaxime in binary mixtures have been estimated by derivative spectrophotometry [10]. CFL and cephalexin in combination have been determined simultaneously by coupling technique of synchronous fluorimetry and $\mathrm{H}$-point standard addition methods [11]. Similarly, CFL and cephalexin have also been determined by HPLC method [12] while CFL and cefuroxime determined in urine by measuring their firstderivative amplitude in $0.1 \mathrm{~N}$ sodium hydroxide at 292.5 and $267.3 \mathrm{~nm}$, respectively. [13].

Ceftriaxone (CFX) is (6R,7R)-7-[[(2Z)-(2amino-4-thiazolyl)(methoxyamino)-acetyl] amino]-8-oxo-3-[ [1, 2, 5,6-tetrahydro-2methyl-5,6-dioxo-1,2,4-triazin-3-yl)-thio] methyl]-5-thia-1-azabicyclo[4.2.0]oct-2-ene-2carboxylic acid [14]. It is a cephalosporin beta-lactum antibiotic used in the treatment of bacterial infections caused by susceptible, usually Gram-positive organisms. The bactericidal activities of CFX result from the inhibition of cell wall synthesis and are mediated through CFX binding to penicillin binding proteins (PBPs). It inhibits mucopeptide synthesis in the bacterial cell wall. The beta lactam moiety of CFX binds to caboxypeptidase, endopeptidase and transpeptidase in the bacterial cytoplasmic membrane. These enzymes are involved in cell wall synthesis and cell division. The binding of CFX to these peptidases results in the formation of defective cell walls and cell death [15].

The monographs for CFX in USP [16] and BP [17] describe an HPLC method for the estimation of the drug in pharmaceutical formulation. Various methods have been developed for CFX determination using HPTLC [18] and spectrophotometry [19]. Simple liquid chromatographic method for the analysis of the blood/brain barrier permeability characteristics of ceftriaxone in an experimental rabbit meningitis model has also been carried out using lignocaine as internal standard [20].

1, 2-naphthoquinone-4-sulphonate (NQS) has been used as a chromogenic reagent for the colorimetric determination of many pharmaceutical amines [21- 23]. However, the reaction of NQS with CFL and CFX has, to the best of our knowledge, not been investigated. The present study describes the evaluation of NQS as a chromogenic reagent in the development of a simple and rapid colorimetric method for the determination of CFL and CFX in pharmaceutical dosage forms.

Trop J Pharm Res, February 2011;10 (1): 82 


\section{EXPERIMENTAL}

\section{Apparatus}

A Shimadzu UV-visible spectrophotometer model 1800, with $1 \mathrm{~cm}$ matched quartz cells, was used for absorbance measurements. Systonics electronic balance (Shimadzu BL$220 \mathrm{H}$ ) was used for weighing the samples.

\section{Reagents and solutions}

All the chemicals employed were of analytical grade and high-purified water was used throughout. Ceftriaxone powder (pure sample) was received as a gift from Strides Arcolab Limited, Bangalore, India while cefadroxil was also provided free of charge by Torrent Pharmaceuticals Ltd, Dist. Mehsana, India.

\section{1, 2-Naphthoquinone-4-sulphonate (NQS) $0.5 \% w / v$}

$0.5 \mathrm{~g}$ of NQS (Loba Chemie Pvt. Ltd, Mumbai, India) was weighed and transferred into a $100 \mathrm{ml}$ calibrated flask, dissolved in 5 $\mathrm{ml}$ distilled water, and made up to the mark with distilled water to obtain a solution of 0.5 $\% \mathrm{w} / \mathrm{v}$. The solution was freshly prepared and protected from light during use.

\section{Sodium hydroxide solution (0.01 M)}

Sodium hydroxide $(0.2 \mathrm{~g})$ was weighed and transferred into a $500 \mathrm{ml}$ volumetric flask and made up to the mark with distilled water.

\section{Standard solutions}

CFL and CFX stock solutions $(1000 \mu \mathrm{g} / \mathrm{ml})$ were prepared separately by dissolving $0.1 \mathrm{~g}$ of each drug in $100 \mathrm{ml}$ of distilled water. Working solutions of the drug were prepared by dilution of the stock solution. The commercial tablet of CFL used in the determination was Droxyl, with a labelled strength of $500 \mathrm{mg}$, and manufactured by
Torrent Pharmaceuticals Limited, Mehsana, India while the injection form of CFX used in the determination was Extacef-i with a labelled quantity of $1 \mathrm{~g}$ on the vial and manufactured by Nitin Life Sciences Limited, Sirmour, India.

\section{Optimization of reaction variables}

\section{Effect of NQS concentration}

The effect of NQS was studied by varying NQS concentrations (Scheme 1). The absorbance of the reaction solution increased as NQS concentration increased, and the highest absorption intensity was attained at NQS concentration of $0.25 \% \mathrm{w} / \mathrm{v}$. Further experiments were carried out using $0.5 \%$.

\section{Effect of alkalinity}

To generate nucleophiles from CFL/CFX and activate nucleophilic substitution reactions, alkaline medium is necessary. The different inorganic bases tested include sodium hydroxide, disodium hydrogen phosphate, and sodium bicarbonate. They were all prepared as aqueous solutions in the concentration range of $0.01-0.05 \mathrm{~N}$.

\section{Preparation of calibration curve}

Standard solutions of CFL and CFX in water, having final concentrations in the range of 10 - $100 \mu \mathrm{g} / \mathrm{ml}$ and $25-175 \mu \mathrm{g} / \mathrm{ml}$, respectively, were transferred into a series of $10 \mathrm{ml}$ volumetric flasks. To each of these solutions, $1 \mathrm{ml}$ of $0.01 \mathrm{M}$ sodium hydroxide was added, followed by $1 \mathrm{ml}$ of $0.5 \%$ NQS. The mixture was then gently shaken until the appearance of orange colour. The contents were diluted to $10 \mathrm{ml}$ with distilled water. The absorbance of each solution was measured at $475 \mathrm{~nm}$ and $480 \mathrm{~nm}$ for CFL and CFX, respectively, against the reagent blank prepared in the same manner, without the analyte. The calibration plots and absorption spectra are represented in the Figs 1 and 2, respectively. 

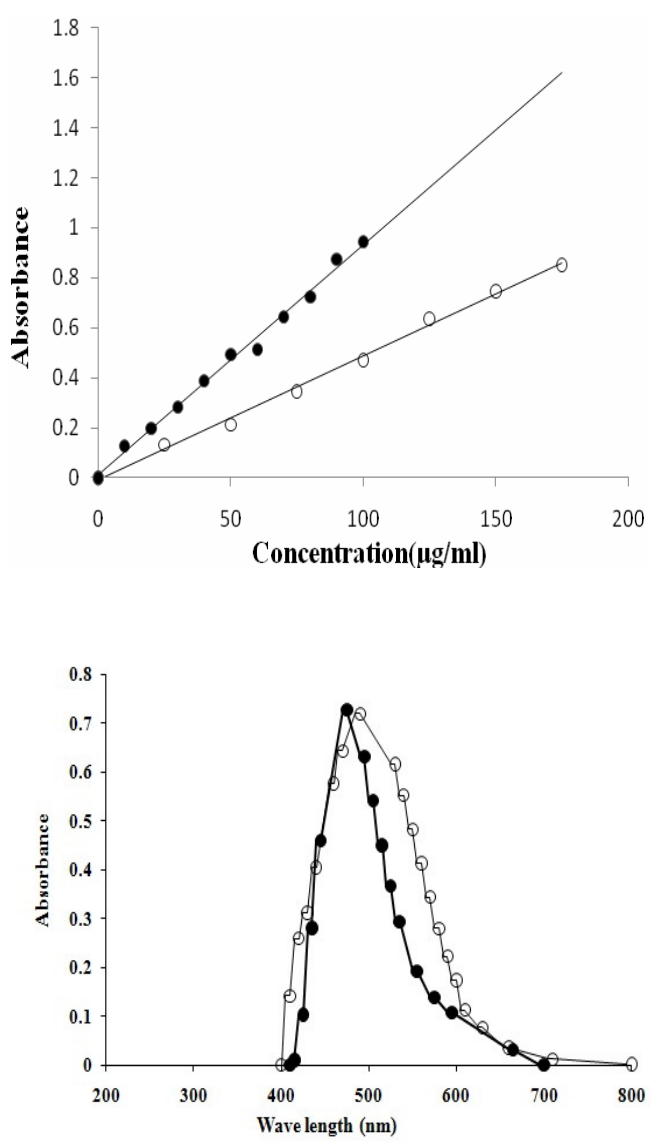

Fig 1: Calibration plots of CFL $(\bullet)$ and CFX (O) with concentration ranges of $10-100$ and $25-175 \mu \mathrm{g} / \mathrm{ml}$, respectively

Fig 2: Absorption spectra of NQS - CFL $(\bullet)$ and NQS - CFX (O), against reagent blank

\section{Analysis of commercial pharmaceutical preparations}

\section{Tablet}

Twenty tablets were weighed, crushed and their contents mixed thoroughly. An accurately weighed portion of the powder, equivalent to the labelled strength $(100 \mathrm{mg})$ of CFL, was taken into a $100 \mathrm{ml}$ volumetric flask containing about $75 \mathrm{ml}$ of distilled water. This was shaken thoroughly for about 5 - 10 min and filtered with Whatman filter paper no. 1 (porosity $11 \mu$ ) to remove insoluble matter.
The filter paper was rinsed severally and the filtrate diluted to mark with distilled water to prepare $1000 \mu \mathrm{g} / \mathrm{ml}$ solution. An aliquot of this solution was diluted with water to obtain a concentration of $50 \mu \mathrm{g} / \mathrm{ml}$. To the sample solution $(0.5 \mathrm{ml}), 1 \mathrm{ml}$ of $0.01 \mathrm{M}$ sodium hydroxide was added, followed by $1 \mathrm{ml}$ of 0.5 $\%$ NQS. The mixture was then gently shaken until the appearance of orange colour. The contents were diluted to $10 \mathrm{ml}$ with distilled water.

\section{Injection}

An appropriate amount of CFX was dissolved in water for injection to prepare $1000 \mu \mathrm{g} / \mathrm{ml}$ solution. An aliquot of this solution was diluted with water to obtain a concentration of $150 \mu \mathrm{g} / \mathrm{ml}$. To the sample solution $(1.5 \mathrm{ml}), 1$ $\mathrm{ml}$ of $0.01 \mathrm{M}$ sodium hydroxide was added, followed by $1 \mathrm{ml}$ of $0.5 \%$ NQS. The mixture was then gently shaken until the appearance of orange colour. The contents were diluted to $10 \mathrm{ml}$ with distilled water.

\section{General procedure}

Series of standard solutions of CFL ( 0.1 to $1.0 \mathrm{ml})$ and CFX $(0.25-1.75 \mathrm{ml})$ were taken in individual standard flasks. To each standard flask, $1 \mathrm{ml}$ of $0.01 \mathrm{M}$ sodium hydroxide and $1 \mathrm{ml}$ of $0.5 \%$ NQS were added. The mixtures were then shaken until the appearance of orange colour. Their absorbance values were measured at $\lambda$ max of 475 and $480 \mathrm{~nm}$ for CFL and CFX, respectively, against a blank similarly prepared by substituting the drug solution with water. The concentration of CFL and CFX in each standard flask was obtained by interpolating the corresponding absorbance value of the product from Beer's plot of standard CFL and CFX solutions.

\section{Quantification}

The limits of Beer's law, the molar absorptivity and the Sandell's sensitivity values for CFL and CFX were evaluated and are given in Table 1. Regression analyses of 
Table 1: Optical parameters $(n=6)$

\begin{tabular}{lcc}
\hline & \multicolumn{2}{c}{ Values } \\
Parameter & Cefadroxil (CFL) & Ceftriaxone (CFX) \\
\hline$\lambda_{\max }(\mathrm{nm})$ & $475 \mathrm{~nm}$ & $480 \mathrm{~nm}$ \\
Beer's law limits $(\mu \mathrm{g} / \mathrm{ml})$ & $10-100$ & $25-175$ \\
Molar absorptivity & $0.458 \times 10^{4}$ & $0.295 \times 10^{4}$ \\
$(\mathrm{~L} / \mathrm{mol} / \mathrm{cm})$ & & \\
Correlation coefficient $(\mathrm{R})$ & 0.993 & 0.995 \\
Sandell's sensitivity $\left(\mathrm{ng} \mathrm{cm} \mathrm{cm}^{-2}\right)$ & 0.079 & 0.1879 \\
Regression equation & $\mathrm{Y}=0.009 \mathrm{X}+0.011$ & $\mathrm{Y}=0.005 \mathrm{X}+0.010$ \\
Slope, $b$ & 0.009 & 0.004 \\
Intercept, $c$ & 0.011 & 0.010 \\
Relative standard deviation $(\%)$ & 0.82 & 0.95 \\
$\%$ Range of error $(95 \%$ confidence limits) & 0.89 & 0.92 \\
Limit of detection $(\mu \mathrm{g} / \mathrm{ml})$ & 10 & 25 \\
Limit of quantification $(\mu \mathrm{g} / \mathrm{ml})$ & 100 & 125 \\
\hline
\end{tabular}

Note: $Y=b X+c$, where $X$ is the concentration of drug in $\mu \mathrm{g} / \mathrm{ml}$

the Beer plots at their respective $\lambda_{\max }$ values revealed a good correlation.

\section{Validation of the method}

The validity of the methods for the assay of CFL and CFX were examined by determining the precision and accuracy. These were determined by analyzing six replicates of the drug within the Beer's law limits. To study the accuracy of the methods, recovery studies were carried out by the standard addition method. For this, known quantities of pure CFL and CFX were mixed with definite amounts of pre-analyzed formulations and the mixtures were analyzed as before. The total amount of the drug was then determined; the amount of the added drug was calculated by difference and the results are given in Table 2 .

\section{Precision}

The precision of the proposed methods was ascertained by actual determination of six replicates of a fixed concentration of each drug within the Beer's law range and determining the absorbance in each case by the proposed method.

\section{Accuracy}

To determine the accuracy of the proposed method, recovery studies were carried out by taking different amounts (80, 100 and $120 \%$ ) of bulk samples of CFL and CFX within the linearity range which were then added to the pre-analyzed formulation of concentrations 50 and $150 \mu \mathrm{g} / \mathrm{ml}$, respectively.

\section{Ruggedness}

To ascertain the ruggedness of the methods, four replicate determinations at different concentration levels of the drugs were carried out. The within-day and inter-day RSD values were determined. The values for different concentrations of drugs obtained from the determinations are given in Table 2 .

\section{RESULTS}

The test method was based on the reaction between NQS and cephalosporin molecules. The NQS reacted with cephalosporin at the free $\mathrm{NH}_{2}$ group as represented in Scheme 1. The reaction was carried out in alkaline medium and best results were obtained with sodium hydroxide. With other bases, either precipitation of a white colloid occurred upon diluting the reaction solution with organic 
solvent, or high blank readings, nonreproducible results, and/or weak sensitivity, were observed. Studies for optimization of sodium hydroxide concentration revealed that the optimum concentration was $0.01 \mathrm{M}$.

Table 2: Analysis, recovery and ruggedness data $( \pm$ SEM, $n=6)$ for CFL tablets and CFX injection by the proposed standard addition method.

\begin{tabular}{ccc}
\hline Sample & $\begin{array}{c}\text { Drug } \\
\text { strength } \\
\text { (mg) }\end{array}$ & $\begin{array}{c}\text { NQS } \\
\text { method }\end{array}$ \\
\hline $\begin{array}{ccc}\text { Cefadroxil } \\
\text { tablets }\end{array}$ & 500 & $100.12 \pm 0.70$ \\
(Droxil-500) & 500 & $100.66 \pm 0.98$ \\
Recovery & 500 & $100.33 \pm 0.52$ \\
Intraday & 500 & $100.53 \pm 0.65$ \\
analysis & & \\
Interday & & \\
analysis & & \\
Ceftriaxone & & \\
injection & 1000 & $99.49 \pm 0.55$ \\
(Extacef ${ }^{\circledR}$-i) & 1000 & $99.38 \pm 0.84$ \\
Recovery & 1000 & $99.12 \pm 0.96$ \\
Intraday & 1000 & $99.58 \pm 0.82$ \\
analysis & & \\
Interday & & \\
analysis & & \\
\hline
\end{tabular}

The reagent blank had negligible absorbance in the range used for the detection of the cephalosporins. As Fig 1 shows, Beer's law was obeyed in the range of $10-100 \mu \mathrm{g} / \mathrm{ml}$ for CFL and $25-175 \mu \mathrm{g} / \mathrm{ml}$ for CFX. Plots of absorbance versus concentration showed the intercept values of about 0.011 and 0.010 for CFL and CFX, respectively; the plots are described by the regression equation, $Y=b X$ $+c$ (where $Y$ is the absorbance of a $1 \mathrm{~cm}$ layer, $b$ is the slope, $c$ is the intercept and $X$ is the concentration of the drug in $\mu \mathrm{g} / \mathrm{ml}$ ) obtained by the least-squares method. The average percent recoveries obtained were quantitative, indicating good accuracy of the methods. The low values of the relative standard deviation (R.S.D.) indicate good precision of the methods. The data indicate that the proposed method has reasonable ruggedness.

\section{DISCUSSION}

Derivatisation using NQS has attracted considerable attention for the quantitative analysis of many pharmaceutically active compounds. In the present investigation, NQS formed a coloured complex with CFL and CFX in alkaline medium and their absorbance maxima were 475 and $480 \mathrm{~nm}$, respectively. Because of the presence of amine as a chromophoric group in CFL and CFX molecules, derivatization of these compounds was attempted in the present study for the development of a colorimetric method for their determination. NQS has been used as a chromogenic and fluorogenic reagent for primary and secondary amines [20]. Therefore, the present study was devoted to explore NQS as a derivatizing reagent in the development of a colorimetric method for the determination of CFL and CFX in pharmaceutical dosage forms. Optimisation of the spectrophotometric conditions was intended to take into account the various goals of method development. Analytical conditions were optimised via a number of preliminary experiments. The effect of NQS concentration was studied and it was found that $0.5 \%$ gave good absorbance values, and so further experiments were carried out using $0.5 \%$ NQS. To generate nucleophiles from CFL and CFX, and activate the nucleophilic substitution reactions, alkaline medium was necessary. Though various inorganic bases were tested such as sodium hydroxide, disodium hydrogen phosphate, and sodium bicarbonate, all were prepared as aqueous solutions in a concentration range of 0.01 $0.05 \mathrm{~N}$. The best results were obtained with sodium hydroxide in a concentration of 0.01 $\mathrm{N}$ solution $(1 \mathrm{ml})$.

Under optimum conditions, the reaction between CFL/CFX and NQS was completed within $2 \mathrm{~min}$ at room temperature, and the absorbance remained unchanged after standing for up to $40 \mathrm{~min}$. The effect of time on the stability of the chromogen was studied by following the absorption intensity of the 
<smiles>N[C@H]([CH]c1ccc(O)cc1)C(=O)N[C@H]1C(=O)N2C(C(=O)O)=CCS[C@H]12</smiles>

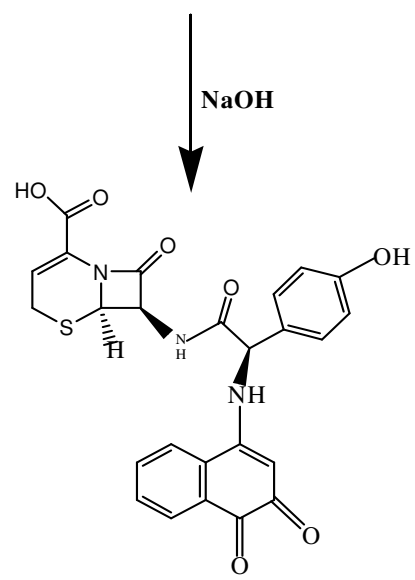

Orange colour complex<smiles>CO/N=C(/C(=O)N[C@H]1C(=O)N2C(C(=O)O)=C(CSc3nc(=O)c(=O)[nH]n3C)CS[C@]12N)c1csc(N)n1</smiles><smiles>O=C1C=C([N+](=O)[O-])C2C=CC=CC12</smiles>

Ceftriaxone (CFX)<smiles>C[C@H](O)[C@@H](C)O</smiles>

Scheme 1: Proposed reaction mechanism for the formation of coloured species reaction solution (after dilution) at different time intervals. It was found that the absorbance of the chromogen remained stable for at least $4 \mathrm{~h}$. This allowed the processing of large batches of samples and their measurement with convenience. In addition to convenience, the methods would also facilitate their applicability to a large number of samples.

\section{CONCLUSION}

The reagents used in the proposed methods are low-cost, readily available and the procedures do not involve any critical reaction conditions or tedious sample preparation. Furthermore, the methods are free from interference by common additives and excipients. The wide applicability of the new procedures in routine quality control was well established by the assay of the cephalosporins (CFL and CFX) in pure form and in pharmaceutical dosage forms.

\section{ACKNOWLEDGEMENT}

The authors express their sincere thanks to Torrent Pharmaceuticals Ltd, Mehsana, India and Strides Arcolab Limited, Bangalore, India for kindly supplying the samples of cefadroxil and ceftriaxone, respectively, used in the study. Thanks are also due to the Principal, JSS College of Pharmacy, Mysore for providing the facilities for this work.

\section{REFERENCES}

1. Bergan T. Pharmacokinetic properties of the cephalosporins. Drugs 1987; 34: 89-104.

2. Abdulrahaman AA, Metwally FH, Al-Tam ASI. Spectrophotometric assay of certain cephalosporins based on formation of ethylene blue. Anal. Lett 1993; 26: 2619-2635.

3. Salem $H$, Askal $H$. Colorimetric and AAS determination of cephalosporins using Reineck's salt. J. Pharm. Biomed. Anal 2002; 29: 347-354.

4. Yang J, Zhou G, Zhang G, Si Z, Hu J. Determination of some cephalosporins in pharmaceutical formulations by a fluorescence quenching method. Anal. Commun 1996; 33: 167-169.

5. Sun $Y$, Tang $Y$, Yao $H$, Zheng $X$. Potassium permanganateglyoxal chemiluminescence

Trop J Pharm Res, February 2011;10 (1): 87 
system for flow injection analysis of cephalosporin antibiotics: cefalexin, cefadroxil, and cefazolin sodium in pharmaceutical preparations. Talanta 2004; 64: 156-159.

6. Ozkan SA, Erk N, Uslu B, Yılmaz N, Biryol I. Study on electrooxidation of cefadroxil monohydrate and its determination by differential pulse voltammetry. J. Pharm. Biomed. Anal 2000; 23: 263-273.

7. Parasrampuria J, Das Gupta V. Quantitation of cefadroxil in pharmaceutical dosage forms using high-performance liquid chromatography. Drug Dev. Ind. Pharm 1990; 16: 1435-1440.

8. Andrasi M, Buglyo P, Zekany L, Gaspar A. A comparative study of capillary zone electrophoresis and $\mathrm{pH}$-potentiometry for determination of dissociation constants. J. Pharm. Biomed.Anal 2007; 44: 1040-1047.

9. Metwally $\mathrm{FH}$, Alwarthan AA, Al-Tamimi SA. Flowinjection spectrophotometric determination of certain cephalosporins based on the formation of dyes. Farmaco 2001; 56: 601-607.

10. Morelli B. Derivative spectrophotometry in the analysis of mixtures of cefotaxime sodium and cefadroxil monohydrate. J. Pharm. Biomed. Anal 2003; 32: 257-267.

11. Yang J, Zhou G, Jie N, Han R, Lin C, Hu J. Simultaneous determination of cephalexin and cefadroxil by using the coupling technique of synchronous fluorimetry and $\mathrm{H}$-point Standard additions method. Anal. Chim. Acta 1996; 325 : 195-200.

12. Shinde VM, Shabadi CV. Simultaneous determination of cefadroxil and cephalexin from capsules by reverse phase HPLC. Indian Drugs 1997; 34: 399-402.

13. El-Gindy A, El Walily AF, Bedair MF. First derivative spectrophotometric and $L C$ determination of cefuroxime and cefadroxil in urine. J. Pharm. Biomed. Anal 2000; 23: 341-352.

14. Budavari S, Ed, The Merck Index. 13th Edn. Merck \& Co., Inc., Whitehouse Station. NJ 2001; p 335.
15. Goodman and Gilman. Chapter 44, The Pharmacological Basis of Therapeutics. $11^{\text {th }}$ edn, 2006.

16. The United States Pharmacopoeia, 26th Revision, U.S. Pharmacopoeial Convention, Inc., Rockville, MD, 2003; $p 386$.

17. British Pharmacopoeia, Vol. I, Her Majesty's Stationary Office, London 2000; $p 329$.

18. Eric-Jovanovic $S$, Agbaba $D$, Zivanov-Stakic $D$ Vladimirov S. HPTLC determination of ceftriaxone, cefixime and cefotaxime in dosage forms. J. Pharm.Biomed. Anal 1998; 18(4-5): 893-898.

19. Agbaba $D$, Eric $S$, Karljikovic-Rajic $K$, Vladimirov S, Zivanov-Stakic D. Spectrophotometric Determination of Certain Cephalosporins Using Ferrihydroxamate Method. Spectroscopy Letters. 1997; 30(2): 309-319.

20. Owens HM, Destache CJ, Dash AK. Simple liquid chromatographic method for the analysis of the blood brain barrier permeability characteristics of ceftriaxone in an experimental rabbit meningitis model. J. Chromat. B: Biomed. Sci. Appl. 1999; 728(1): 97- 105.

21. Ashraf MM, Nasr $K Y$, Ibrahim DA, Tarek $A$. Selective Spectrophotometric and Spectrofluorometric Methods for the Determination of Amantadine Hydrochloride in Capsules and Plasma via Derivatization with 1, 2Naphthoquinone-4-sulphonate. Int J Anal Chem 2009; 10: 1155-1162.

22. Li Q-M, Li J, Yang Z-J. Study of the sensitization of tetradecyl benzyl dimethyl ammonium chloride for spectrophotometric determination of dopamine hydrochloride

using sodium 1,2-naphthoquinone-4-sulfonate as the chemical derivative chromogenic

reagent, Analytica Chimica Acta 2007; 583(1): 147152.

23. Hasani M, Yaghoubi L, Abdollahi H. A kinetic spectrophotometric method for simultaneous determination of glycine and lysine by artificial neural networks, Anal Biochem 2007; 365(1): 74-81. 